\title{
The potential impact of low thermal transmittance construction on the European design guidelines of residential buildings
}

\author{
Eugénio Rodrigues ${ }^{\mathrm{a}, \mathrm{c}, *}$, Marco S. Fernandes ${ }^{\mathrm{a}}$, Nelson Soares ${ }^{\mathrm{a}, \mathrm{b}}$, \\ Álvaro Gomes ${ }^{c, d}$, Adélio Rodrigues Gaspara ${ }^{\mathrm{a}}$, José J. Costa ${ }^{\mathrm{a}}$ \\ ${ }^{a}$ ADAI, LAETA, Department of Mechanical Engineering, University of Coimbra \\ Rua Luís Reis Santos, Pólo II, 3030-788 Coimbra, Portugal \\ ${ }^{b}$ ISISE, Department of Civil Engineering, University of Coimbra \\ Rua Luís Reis Santos, Pólo II, 3030-788 Coimbra, Portugal \\ ${ }^{c}$ INESC Coimbra - Institute for Systems Engineering and Computers in Coimbra \\ Rua Sílvio Lima, Pólo II, 3030-290 Coimbra, Portugal \\ ${ }^{d}$ Department of Electrical and Computer Engineering, University of Coimbra \\ Rua Sílvio Lima, Pólo II, 3030-290 Coimbra, Portugal
}

\begin{abstract}
European countries impose regulations for low thermal transmittance envelopes to improve the buildings' energy efficiency. However, in scientific literature, evidences are surfacing that such low $U$-values are affecting the validity of traditional design guidelines. The purpose of this paper is to analyze the implications of lowering the envelope $U$-values. To achieve this, 96000 residential buildings were generated, with random geometries and $U$-values, and their energy consumption evaluated for eight European locations. The buildings were grouped according to the envelope elements' thermal transmittance and the results statistically analyzed. For each group, six geometry-based indexes were correlated with the energy performance. As $U$-values decrease, the performance variation amplitude was found to reduce, making the geometry less important. However, in warm/moderate climates, low $U$-values tend to actually increase the energy consumption and also rise the performance variation, meaning that geometry regains importance. In this case, instead of helping reducing the heating demands, solar exposed windows and compact geometries raise the energy consumption. It is concluded that, for each climate location, there is an ideal $U$-value range for which the energy demand is low and the geometry effect becomes less significant, thus freeing designers to further explore building forms and window designs.
\end{abstract}

Keywords: generative design method, dynamic simulation, residential buildings, building geometry, thermal transmittance

\footnotetext{
${ }^{*}$ Corresponding author.

Email address: erodrigues@uc.pt (Eugénio Rodrigues)
} 


\section{Introduction}

As stated by Soares et al. [1], debates addressing fossil fuels depletion, climate change, and energy security emphasize the need for a more sustainable built environment in order to reduce energy consumption and emission trends in the buildings sector. To achieve this, researchers are studying the relation between the envelope thermal properties, geometry, and the use of dynamic systems to determine the impacts on the energy performance of buildings.

Vanhoutteghem and Svendsen [2] analyzed well-insulated residential buildings in Denmark concerning the choice of the size, type and orientation of windows. The authors concluded that modern insulation requirements can change some of the traditional guidelines of architectural design in lowenergy residential buildings, and that windows can be positioned in the facades with considerable architectural freedom. Figueiredo et al. [3] studied the application of the Passive House concept in Portugal using simulation in four locations. The authors performed sensitivity analysis and optimization of the construction elements and building orientation in a single-family house and determined that passive house is viable despite the risk of overheating if no shadowing is used to dispense with active cooling. Vanhoutteghem et al. 4] evaluated the impact of the size, orientation and glazing properties of window facades on the energy consumption, daylight and thermal comfort of Danish nearly zero-energy buildings (nZEB). These authors underlined the need for a design that takes into account winter and summer conditions in order to reduce the energy demand for both heating and cooling (avoiding overheating problems). In Southern European countries, the nZEB problem of overheating results from the combination of air tightness, insulation level, thermal mass, lack of solar protection, and absence of passive cooling and of air velocity control within occupied spaces [5]. However, these results were based on interviewing experts, mainly researchers from the studied countries, and aimed to carry out a cross comparison on the current trends and state of nZEB implementation in Southern European countries.

Goia [6] has also pointed out the importance of searching for the optimum window-to-wall ratio $(W W R)$ on an annual basis. The author determined the optimal $W W R$ in office buildings for Oslo, Frankfurt, Rome and Athens climates and its influence in the total energy saving. It was concluded that most of the ideal $W W R$ values are found in the range of 0.30 to 0.45 , which can represent a $5 \%$ to $25 \%$ improvement in the total energy use. Ma et al. [7] aimed to show the effectiveness of process assumption-based design (understanding buildings as dynamic thermal systems) together with heat balance design as a tool to achieve real buildings' energy savings. The authors evaluated the relationship between the maximum $W W R$ of a thermally autonomous building and the ambient temperature amplitudes with different envelope thermal resistances. Assem [8] correlated thermal transmittance maximum value for walls and roofs with the element orientation and solar absorption 
coefficient. The author determined that these factors have a high effect on the $U$-value, particularly for roofs and walls facing West and East orientations. Amaral et al. [9] found that double and triple glazing windows facing North contribute positively to the zone thermal comfort, due to the diffuse solar radiation gains being greater than the losses by thermal transmittance, in Coimbra (Portugal). The same study also shows that windows facing North, or windows facing other orientations that are protected with overhangs, can even have larger glazing areas together with a small thermal comfort improvement. Rodrigues et al. [10] found evidence that traditional design guidelines may not be currently valid for warmer climates and specific building types. The authors suggest that this may result from the low thermal transmittance values of the envelope elements, which changed the relations between the building geometry and the building performance that were found in past studies.

Stazi et al. [11] studied the impact of high thermal insulation and high thermal mass techniques on buildings dynamics in two single-family houses in Italy, to define retrofit strategies. The authors found that high insulation and high thermal mass are conflicting approaches, since combining the dynamic strategies of daily natural ventilation, inner mass and vented external walls allowed to obtain optimum summer comfort and winter and summer energy savings. Following the theoretical benefits of adjusting the building construction envelope to the outside conditions, researchers seek dynamic or smart building elements that can change their thermal properties. For instance, Kimber et al. [12 proposed a switchable multifunctional smart insulation to provide the wall with high insulation and conductive configuration to allow the wall and roofs to switch between high thermal resistance and conductive states. The concept of the proposed smart insulation consists of switching inflating/deflating interstitial thin polymer membranes with air to make negligible natural convection or to achieve low thermal resistance. Following the same idea of changeable thermal properties, Pflug et al. [13] modeled a switchable $U$-value for the building transparent facade element. The proposed construction consisted of a double-glazing unit with a translucent insulation panel that controls the internal convective flow around this panel. Craig and Grinham [14] studied the design of pores in breathing walls that consist of porous materials capable of tempering efficiently the incoming fresh air with minimum heat losses by conduction, thus making the building envelopes a kind of heat-exchangers with good prospects to exploit low-grade heat.

The above-mentioned studies cover a single construction element solution or a set of construction solutions for a small number of buildings. As stated by Attia et al. [5] in their overview on the implementation of nZEB in Southern Europe, it cannot be claimed statistical representation of their findings and there is a lack of cross comparison on the current trends and state of low-energy buildings implementation. Therefore, the purpose of this work is to statistically capture the overall trend of changing the $U$-values in a large set of buildings in different climate locations in Europe. 
As the design of an energy efficient well-insulated building requires specific design guidelines that match the new construction thermophysical properties, this paper also investigates the impact of varying $U$-values on the building geometry guidelines. To achieve this, a number of residential buildings were randomly generated with random $U$-values of the envelope elements for eight different European climates, in order to provide a significant sample of buildings to statistically analyze the energy performance. The EPSAP algorithm was used as a building generative design method, consisting of a computerized approach that determines the interior arrangement according to a set of design requirements [15 17]. The generated buildings were then evaluated using the coupled dynamic simulation program EnergyPlus [18, 19]. Afterwards, for each group of buildings with similar $U$-values, six geometry-based indexes were correlated with the buildings energy performance: volume $(V)$, shape coefficient $\left(C_{f}\right)$, relative compactness $(R C)$, window-to-floor ratio $(W F R)$, window-to-wall ratio $(W W R)$, and window-to-surface ratio $(W S R)$, as geometry-based indexes have shown to be capable of capturing the relation of a few geometric variables with the performance of the building [20 27]. By this way, it is discussed if the design guidelines for low $U$ values of the buildings' envelope elements are still valid. It is expected to find that different design guidelines may be applicable for different $U$-value intervals, according to the outdoor conditions in each climate location, particularly for southern countries.

This approach of creating a synthetic dataset of a great number of buildings to analyze the impact of construction thermophysical properties in the performance and geometric aspects of the buildings and to determine general guidelines is a novel and never before accomplished approach. Moreover, the results are a helpful instrument for the early design stages, where the building geometry is still vague or missing, or when developing new optimization tools that seek to accommodate all kind of design variables, thus placing the starting searching point within the range of the most favorable construction solution.

\section{Methodology}

To determine the influence of the $U$-values variation on the building geometry of eight European locations (Lisbon - Portugal, PRT; Toledo - Spain, ESP; Porto - PRT; Bucharest - Romania, ROU; Milan - Italy, ITA; Paris - France, FRA; Stockholm - Sweden, SWE; and Kiruna - SWE), two-story residential buildings will be randomly generated using a hybrid evolution strategy [1517] and their energy consumption evaluated using dynamic simulation [18, 19]. The construction system will have random $U$-values for the exterior opaque and transparent elements, ranging from $0.1 \mathrm{~W} \cdot \mathrm{m}^{-2} \cdot \mathrm{K}^{-1}$ to $1.5 \mathrm{~W} \cdot \mathrm{m}^{-2} \cdot \mathrm{K}^{-1}$ and from $0.4 \mathrm{~W} \cdot \mathrm{m}^{-2} \cdot \mathrm{K}^{-1}$ to $6.0 \mathrm{~W} \cdot \mathrm{m}^{-2} \cdot \mathrm{K}^{-1}$, respectively. The thermal inertia is kept the same in all buildings. The generated data will be divided by pairs of transparent/opaque $U$-values and the energy performance range will be determined. 
1 For each group, the performance will then be correlated with six geometry-based indexes (three 2 related with building shape and three related to windows). Finally, the results will be analyzed

3 and the changes in the building design guidelines discussed.

\section{2.1. Geometry-based indexes}

To study the impact of varying the thermal transmittance of the building envelope elements, six geometry-based indexes were chosen - building volume, two building compactness indexes, and three window-based indexes. The simplest of all is the building volume $(V)$. As all generated buildings will have the same design program (same rooms within the same geometric and topologic constraints) and usage profiles (thermal zones with the same occupation, artificial lighting, ventilation, infiltration, air-conditioning thermostat, etc.), the variation of the volume provides an easy and initial analysis of the results. Then, the commonly used shape coefficient $\left(C_{f}=S / V\right.$ $\left[\mathrm{m}^{-1}\right]$ ) [20], also known as shape factor, will be used. The third index is the relative compactness $\left(R C=6 V^{2 / 3} / S\right)$. Past studies have shown this index to be more reliable than the shape coefficient [10, 28].

The last three indexes are based on ratios of the window areas $\left(S_{\text {win }}\right)$ in the building to the building floor areas $\left(W F R=S_{\text {win }} / S_{\text {floor }}\right)$, exterior wall areas $\left(W W R=S_{\text {win }} / S_{\text {wall }}\right)$, and overall surface areas in contact with the outdoor ambient $\left(W S R=S_{w i n} / S\right)$. As $W S R$ captures better the impact of the exterior opaque elements and their relation with the window areas [10], each cardinal orientation of this index was also analyzed (WSR-N,WSR-E, WSR-S, and WSR-W for North, East, South, and West orientations, respectively).

\subsection{Generative design method}

The generative design method used to create the building designs was a new version of the Evolutionary Program for the Space Allocation Program (EPSAP) algorithm, presented in refs. 15 17, which produces alternative space arrangements according to the user preferences and requirements, and has been developed under the research project Ren4EEnIEQ [29]. This newer version uses an updated floor plan representation scheme - which incorporates negative spaces, free position of interior openings, different types of opening's frame, and stairs can now have exterior openings - and a set of new penalty functions, which constitute the layout gross and construction area function, the story gross area function, the circulation space area function, the space fixed position function, the space relative importance function, the opening accessibility function, and the opening fixed position function. When the floor plan generation is complete, the energy performance of the generated solutions is then evaluated using EnergyPlus [18, 19].

Shortly, the EPSAP algorithm is a hybrid Evolution Strategy (ES) approach, where the mutation operation is replaced by a Stochastic Hill Climbing (SHC) method, which performs random 

summarizes the specified requirements.

Table 1. Rooms' geometry and topologic specifications.

\begin{tabular}{|c|c|c|c|c|c|c|c|c|c|}
\hline Room & $C^{s n}$ & $C^{s f}$ & $C^{r i}$ & $C^{s l}$ & $C^{s u}$ & $C^{s s}(\mathrm{~m})$ & $C^{s a}\left(\mathrm{~m}^{2}\right)$ & $C^{s s r}$ & $C^{s l r}$ \\
\hline$S_{1}$ & Hall & Circulation & Min & $L_{1}$ & $L_{1}$ & 2.70 & 10.0 & $\{2.0,3.0\}$ & $\{3.0,1.5\}$ \\
\hline$S_{2}$ & Living room & Living & $\operatorname{Max}$ & $L_{1}$ & $L_{1}$ & 3.20 & - & 1.7 & 2.0 \\
\hline$S_{3}$ & Kitchen & Service & Mid & $L_{1}$ & $L_{1}$ & 1.80 & - & 1.7 & 2.0 \\
\hline$S_{4}$ & Bathroom & Service & Min & $L_{1}$ & $L_{1}$ & 2.20 & - & 1.7 & 2.0 \\
\hline$S_{5}$ & Stair & Circulation & - & $L_{1}$ & $L_{2}$ & - & - & - & - \\
\hline$S_{6}$ & Corridor & Circulation & None & $L_{2}$ & $L_{2}$ & 1.40 & 6.0 & $\{2.0,3.0\}$ & $\{3.0,1.5\}$ \\
\hline$S_{7}$ & Double bedroom & Living & High & $L_{2}$ & $L_{2}$ & 2.70 & - & 1.7 & 2.0 \\
\hline$S_{8}$ & Main bedroom & Living & High & $L_{2}$ & $L_{2}$ & 2.70 & - & 1.7 & 2.0 \\
\hline$S_{9}$ & Single bedroom & Living & Mid & $L_{2}$ & $L_{2}$ & 2.70 & - & 1.7 & 2.0 \\
\hline$S_{10}$ & Bathroom & Service & Min & $L_{2}$ & $L_{2}$ & 2.20 & - & 1.7 & 2.0 \\
\hline \multicolumn{10}{|c|}{$\begin{array}{l}C^{s n} \text { - name, } C^{s f}-\text { function, } C^{r i}-\text { relative importance, } C^{s l} \text { and } C^{s u} \text { - served lower and upper stories, } \\
C^{s s} \text { - minimum side, } C^{s a} \text { - minimum area, } C^{s s r} \text { and } C^{s l r} \text { - space small side and large side ratios }\end{array}$} \\
\hline
\end{tabular}

geometric and topologic transformations, and a selection mechanism that picks up the fittest individuals for the next generation. The SHC transformations are a set of actions, such as translation, rotation, stretching, reflection, and swapping, which are applied to a single or a group of floor plan elements (openings, rooms, cluster of rooms), or to the whole floor plan. By combining these two methods into a single hybrid algorithm, it is possible to benefit from the known capabilities of a global search by the former and a local search by the latter, thus consisting of a two-stage approach.

\subsection{Building specifications}

The building specifications focus on the geometry constraints and requirements, construction system, indoor specifications, and climate locations. The geometry specifications focus on the geometry data that are used in the EPSAP algorithm to generate alternative buildings for the same design program. The construction system defines the elements, physical properties and the range of $U$-values for opaque and transparent elements that are randomly selected to each building geometry. The occupancy, equipment, lighting, HVAC, and other usage profiles are defined for each thermal zone (space/room) and are equal in every generated building. Lastly, the chosen European locations are characterized according to their climate and geographic position.

\subsubsection{Geometry constraints and requirements}

The building is a two-story residential single-family house without boundaries or adjacent buildings, and with no specific orientation. The aimed height for each story is $2.70 \mathrm{~m}$. The first floor level $\left(L_{1}\right)$ comprises a hall $\left(S_{1}\right)$, a living room $\left(S_{2}\right)$, a kitchen $\left(S_{3}\right)$, and a bathroom $\left(S_{4}\right)$, and it is served by a stair $\left(S_{5}\right)$ connecting to the second floor level $\left(L_{2}\right)$, which has a corridor $\left(S_{6}\right)$, a double bedroom $\left(S_{7}\right)$, a main bedroom $\left(S_{8}\right)$, a single bedroom $\left(S_{9}\right)$, and a bathroom $\left(S_{10}\right)$. Table 1

Each space/room may have exterior openings (windows or doors). For instance, the hall $\left(S_{1}\right)$ has an opening $\left(O e_{1}\right)$ of type door $\left(C^{o e t}\right)$, with $1.0 \mathrm{~m}$ width $\left(C^{o e w}\right), 2.0 \mathrm{~m}$ height $\left(C^{o e h}\right)$, and is 
1 elevated $0.0 \mathrm{~m}$ from the floor $\left(C^{\text {oev }}\right)$. Table 2 lists all exterior openings in the design program per space $\left(C^{o s}\right)$.

Table 2. Geometry specifications of exterior openings.

\begin{tabular}{lclccc}
\hline$C^{\text {os }}$ & Opening & $C^{\text {oet }}$ & $C^{\text {oew }}(\mathrm{m})$ & $C^{\text {oeh }}(\mathrm{m})$ & $C^{\text {oev }}(\mathrm{m})$ \\
\hline$S_{1}$ & $O e_{1}$ & Door & 1.00 & 2.00 & 0 \\
$S_{2}$ & $O e_{2}$ & Window & 2.80 & 2.00 & 0 \\
$S_{3}$ & $O e_{3}$ & Window & 1.20 & 1.00 & 1.00 \\
$S_{4}$ & $O e_{4}$ & Window & 0.60 & 0.60 & 1.40 \\
$S_{5}$ & $O e_{5}$ & Window & 0.80 & 1.40 & 0.80 \\
$S_{6}$ & - & - & - & - & - \\
$S_{7}$ & $O e_{6}$ & Window & 1.80 & 1.00 & 1.00 \\
$S_{8}$ & Oe & Window & 1.80 & 1.00 & 1.00 \\
$S_{9}$ & Oe & Window & 1.20 & 1.00 & 1.00 \\
$S_{10}$ & - & - & - & - & - \\
\hline$C^{\text {os }}-$ space, $C^{\text {oet }}-$ opening type, $C^{\text {oew }}-$ minimum width, \\
$C^{\text {oeh }}-$ minimum height, $C^{\text {oev }}-$ vertical position \\
\hline
\end{tabular}
considered (e.g., $\left.O i_{5}\right)$. Table 3 lists all the interior openings in the building.

Table 3. Interior openings geometry and topologic specifications.

\begin{tabular}{clccccc}
\hline Opening & $C^{\text {oit }}$ & $C^{\text {oia }}$ & $C^{\text {oib }}$ & $C^{\text {oiw }}(\mathrm{m})$ & $C^{\text {oih }}(\mathrm{m})$ & $C^{\text {oiv }}(\mathrm{m})$ \\
\hline$O i_{1}$ & Door & $S_{1}$ & $S_{2}$ & 1.40 & 2.00 & 0 \\
$O i_{2}$ & Door & $S_{1}$ & $S_{3}$ & 0.90 & 2.00 & 0 \\
$O i_{3}$ & Door & $S_{1}$ & $S_{4}$ & 0.90 & 2.00 & 0 \\
$O i_{4}$ & Door & $S_{5}$ & $S_{1}$ & 0.90 & 2.00 & 0 \\
$O i_{5}$ & Adjacency & $S_{2}$ & $S_{3}$ & 0 & - & - \\
$O i_{6}$ & Door & $S_{5}$ & $S_{6}$ & 0.90 & 2.00 & 0 \\
$O i_{7}$ & Door & $S_{6}$ & $S_{7}$ & 0.90 & 2.00 & 0 \\
$O i_{8}$ & Door & $S_{6}$ & $S_{8}$ & 0.90 & 2.00 & 0 \\
$O i_{9}$ & Door & $S_{6}$ & $S_{9}$ & 0.90 & 2.00 & 0 \\
$O i_{10}$ & Door & $S_{6}$ & $S_{10}$ & 0.90 & 2.00 & 0 \\
\hline$C^{\text {oit }}-$ type, $C^{\text {oia }}-$ opening's space, $C^{\text {oib }}-$ destination space, \\
$C^{\text {oiw }}-$ minimum width, $C^{\text {oih }}-$ minimum height, C $C^{\text {oiv }- \text { vertical position }}$ \\
\hline
\end{tabular}
Otherwise, when there is only adjacency between spaces but no opening, a $0.0 \mathrm{~m}$ wide opening is

\subsubsection{Construction system} tion (see Table 4), while the $U$-value is randomly changed throughout the dynamic simulations elements $\left(0.4 \mathrm{~W} \cdot \mathrm{m}^{-2} \cdot \mathrm{K}^{-1}\right.$ to $6.0 \mathrm{~W} \cdot \mathrm{m}^{-2} \cdot \mathrm{K}^{-1}$, in steps of $\left.0.2 \mathrm{~W} \cdot \mathrm{m}^{-2} \cdot \mathrm{K}^{-1}\right)$.

Besides exterior openings, the spaces may have adjacent or connectivity requirements. For example, the interior opening $\left(O i_{1}\right)$ of type door $\left(C^{o i t}\right)$, with $1.4 \mathrm{~m}$ width $\left(C^{\text {oiw }}\right), 2.0 \mathrm{~m}$ height $\left(C^{\text {oih }}\right)$, and $0.0 \mathrm{~m}$ elevation from the floor $\left(C^{\text {oiv }}\right)$, connects space $S_{1}\left(C^{\text {oia }}\right)$ to space $S_{2}\left(C^{\text {oib }}\right)$.

Regarding construction parameters, the building is characterized by having strong inertia with current material properties. Table 4 presents the building's opaque and transparent elements. For all the exterior opaque elements apart from doors (exterior walls, roofs, and suspended slabs), the elements were designed to have a thermal mass equivalent to that of the interior slab construc$\left(0.1 \mathrm{~W} \cdot \mathrm{m}^{-2} \cdot \mathrm{K}^{-1}\right.$ to $1.5 \mathrm{~W} \cdot \mathrm{m}^{-2} \cdot \mathrm{K}^{-1}$, in steps of $\left.0.05 \mathrm{~W} \cdot \mathrm{m}^{-2} \cdot \mathrm{K}^{-1}\right)$. The same $U$-values are also applied to the exterior doors. For the windows, the glazing type has a constant solar heat gain coefficient (SHGC) of 0.6 and variable $U$-values proportionally paired with those of the opaque 
Table 4. Building's construction elements.

\begin{tabular}{|c|c|c|c|c|c|c|c|}
\hline Element & Layer & Thickness (m) & $k\left(\mathrm{~W} \cdot \mathrm{m}^{-1} \cdot \mathrm{K}^{-1}\right)$ & $\rho\left(\mathrm{kg} \cdot \mathrm{m}^{-3}\right)$ & $c_{p}\left(\mathrm{~J} \cdot \mathrm{kg}^{-1} \cdot \mathrm{K}^{-1}\right)$ & $U\left(\mathrm{~W} \cdot \mathrm{m}^{-2} \cdot \mathrm{K}^{-1}\right)$ & SHGC \\
\hline \multirow{3}{*}{ Interior wall } & Finishing layer & 0.02 & 0.22 & 950 & 840 & \multirow{3}{*}{4.499} & - \\
\hline & Structural layer & 0.07 & 1.73 & 2243 & 836.8 & & \\
\hline & Finishing layer & 0.02 & 0.22 & 950 & 840 & & \\
\hline \multirow{4}{*}{ Interior slab } & Finishing layer & 0.02 & 0.22 & 950 & 840 & \multirow{4}{*}{2.841} & - \\
\hline & Structural layer & 0.2 & 1.73 & 2245.6 & 836.8 & & \\
\hline & Regulation layer & 0.01 & 0.22 & 950 & 840 & & \\
\hline & Finishing layer & 0.02 & 0.2 & 825 & 2385 & & \\
\hline \multirow{5}{*}{ Ground floor } & Structural layer & 0.2 & 1.73 & 2245.6 & 836.8 & \multirow{5}{*}{0.437} & - \\
\hline & Insulation layer & 0.08 & 0.04 & 32.1 & 836.8 & & \\
\hline & Filling layer & 0.02 & 0.8 & 1600 & 840 & & \\
\hline & Regulation layer & 0.01 & 0.22 & 950 & 840 & & \\
\hline & Finishing layer & 0.02 & 0.2 & 825 & 2385 & & \\
\hline \multirow{3}{*}{ Interior door } & Finishing layer & 0.005 & 0.2 & 825 & 2385 & \multirow{3}{*}{2.009} & - \\
\hline & Structural layer & 0.03 & 0.067 & 430 & 1260 & & \\
\hline & Finishing layer & 0.005 & 0.2 & 825 & 2385 & & \\
\hline Exterior window & - & - & - & - & - & $\operatorname{RAND}\{0.4, \cdots, 6.0\}$ & 0.6 \\
\hline Envelope elements & \multicolumn{5}{|c|}{ Internal mass equivalent to Interior slab } & $\operatorname{RAND}\{0.1, \cdots, 1.5\}$ & - \\
\hline
\end{tabular}

\subsubsection{Occupancy, equipment, lighting, and HVAC specifications}

The characterization of the occupancy patterns and the operation schedules of appliances and 3 lighting is done based on the building typology. Regarding occupancy, five people are considered 4 to inhabit the building, distributed in the different zones according to the occupancy patterns 5 depicted in Fig. 1. The maximum assumed number of people per zone and the respective activity level, which accounts for the internal heat gains due to occupancy, are presented in Table 5.

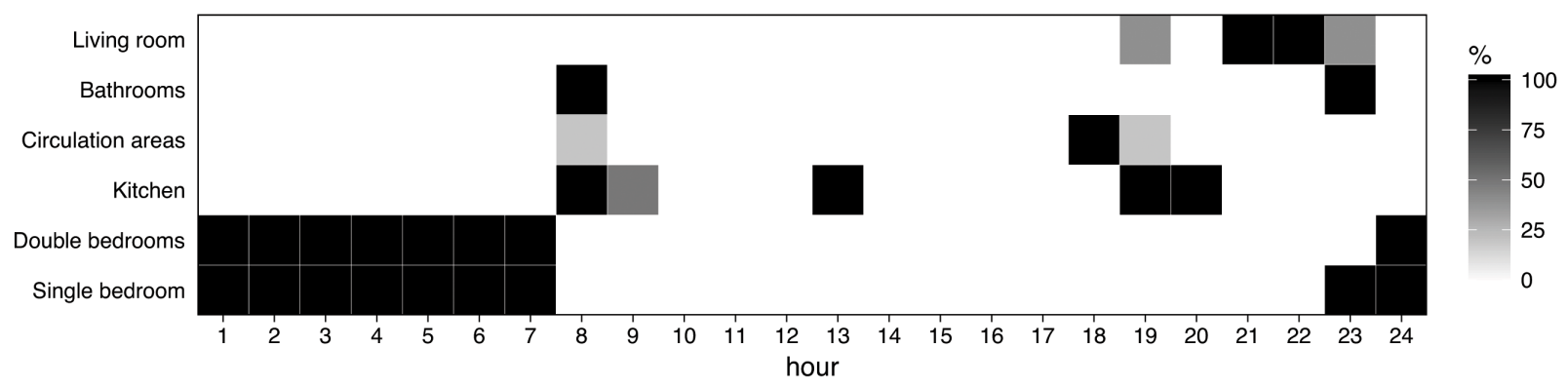

Fig. 1. General occupancy pattern in the building zones.

Table 5. Maximum number of people per zone and corresponding activity levels.

\begin{tabular}{lcc}
\hline Zone type & Max number of people $^{a}$ & Activity level (W.person $^{-1}$ ) \\
\hline Living room & 5 & 110 \\
Bathrooms & 1 & 207 \\
Circulation areas & 1 & 190 \\
Kitchen & 2 & 190 \\
Double/Main bedroom & 2 & 72 \\
Single bedroom & 1 & 72 \\
\hline$a$ - Regarding the building inhabitants accessing each zone, and not necessarily the number \\
of occupants simultaneously in the zone. The occupant's distribution is defined together \\
with the proper occupancy schedules.
\end{tabular}

The maximum design lighting levels for each zone are presented in Table6. The lighting schedules are based on the building zone typology, occupancy, and window shading, and are depicted 

the electric lighting profiles are identical in all locations.

Table 6. Maximum design lighting levels for each zone type.

\begin{tabular}{lc}
\hline Zone type & Design lighting level $\left(\mathrm{W} \cdot \mathrm{m}^{-2}\right)$ \\
\hline Living room/Bedrooms & 7.5 \\
Bathrooms & 0.5 \\
Circulation areas & 3.2 \\
Kitchen & 5 \\
\hline
\end{tabular}

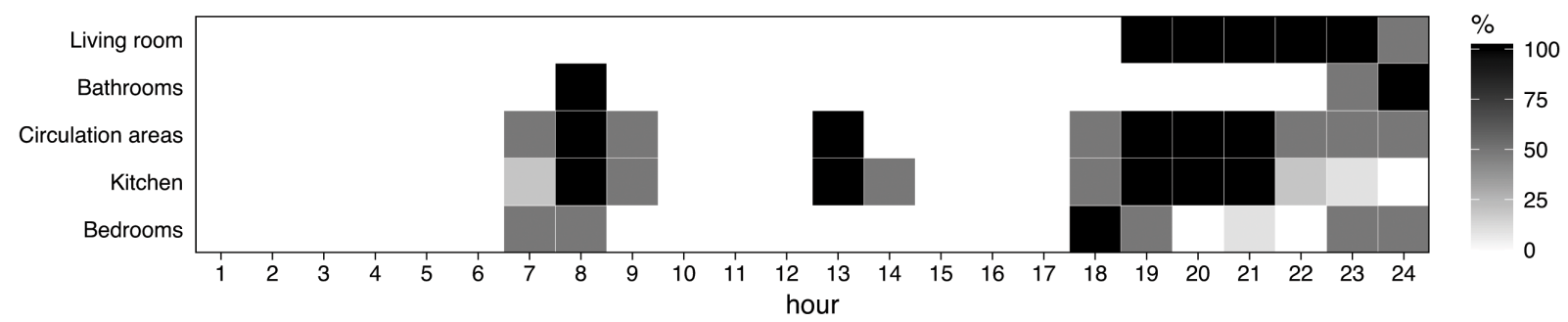

Fig. 2. Electric lighting schedule in each zone. occupancy, which are depicted in Fig. 3 for the different zones.

Table 7. Total heat gains from electric equipment in each zone.

\begin{tabular}{lc}
\hline Zone type & Design level $(\mathrm{W})$ \\
\hline Living room & 350 \\
Bathrooms & 100 \\
Circulation areas & 20 \\
Kitchen & 1440 \\
Bedrooms & 250 \\
\hline
\end{tabular}

The internal heat gains due to electric equipment are defined by the maximum design wattage levels of the appliances typically found in each zone, which are based on the building zone typology (Table 7). The corresponding usage schedules are based on the building zone typology and

An overall exhaust ventilation rate of 0.6 air-changes per hour $(\mathrm{ACH})$ is considered in the model for the kitchen and bathrooms zones. The exhaust flow rate profiles correspond to the occupation schedules defined for these two zones - Fig. 1. Regarding the outdoor air infiltration into the building, it is considered constant as $0.2 \mathrm{ACH}$ for zones with exterior openings and as $0.1 \mathrm{ACH}$ for zones without exterior openings. The building's living areas (living room and bedrooms) are air-conditioned considering an ideal loads air system model in the EnergyPlus runs, which allows to 


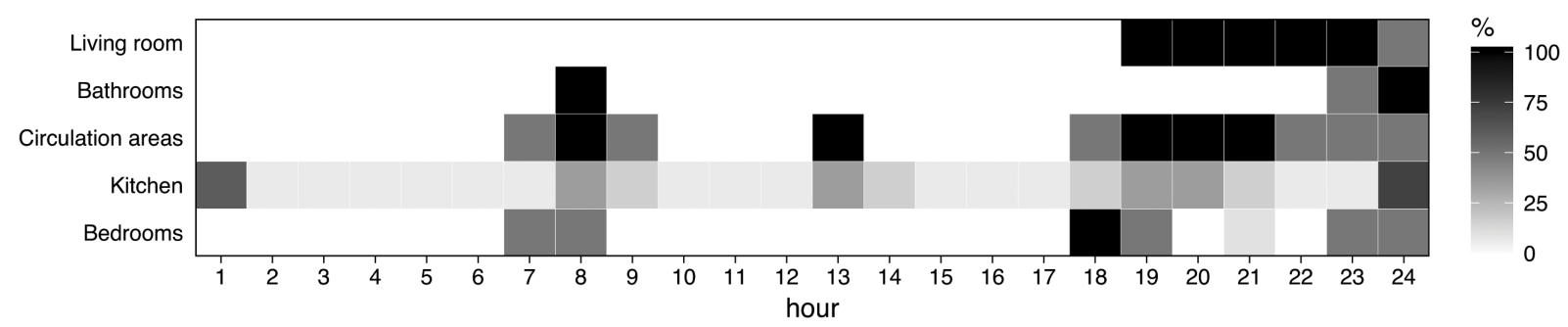

Fig. 3. Electric equipment schedules in each zone.

assess the performance of the building without modelling a full HVAC system, meeting all the load requirements and consuming no energy [30]. The air temperature thermostat is set with a cooling setpoint temperature of $25.0^{\circ} \mathrm{C}$ and a heating setpoint of $20.0^{\circ} \mathrm{C}$, following the Portuguese energy conservation code [31, which is assumed for all the case studies. A $50 \%$ dehumidification setpoint is also considered [31. The air-conditioning availability schedules for each zone correspond to the occupation schedules defined for the respective zones - Fig. 1.

\subsubsection{Climate locations}

For this study, eight locations were selected having different climate types, according to the Köppen-Geiger World Map climate classification [32] - Lisbon (PRT), Toledo (ESP), Porto (PRT), Milan (ITA), Bucharest (ROU), Paris (FRA), Stockholm (SWE), and Kiruna (SWE). The chosen climates seek to cover most of the climate types in Europe, such as Mediterranean climate, dry semiarid, humid subtropical and continental, marine west coastal, moist continental, and subartic. The weather data from these locations were downloaded from the EnergyPlus website [33]. Figure 4 illustrates the locations in Europe and Table 8 summarizes the corresponding climates (type and description) and the geographic references (country, latitude, longitude, and altitude).

Table 8. Climate classification of each location.

\begin{tabular}{rlrrrll}
\hline \multirow{2}{*}{ City } & Country & $\begin{array}{r}\text { Lation } \\
\text { Latude }\end{array}$ & Longitude & Altitude (m) & Type & Climate description \\
\hline Lisbon & Portugal (PRT) & $38.73 \mathrm{~N}$ & $9.15 \mathrm{~W}$ & 71 & Csa & Mediterranean climate (dry hot summer, mild winter) \\
Toledo & Spain (ESP) & $39.88 \mathrm{~N}$ & $4.05 \mathrm{~W}$ & 529 & BSk & Mid-latitude dry semiarid \\
Porto & Portugal (PRT) & $41.23 \mathrm{~N}$ & $8.68 \mathrm{~W}$ & 73 & Csb & Mediterranean climate (dry warm summer, mild winter) \\
Bucharest & Romania (ROU) & $44.50 \mathrm{~N}$ & $26.13 \mathrm{E}$ & 91 & Dfa & Humid continental (hot summer, cold winter, no dry season) \\
Milan & Italy (ITA) & $45.62 \mathrm{~N}$ & $8.73 \mathrm{E}$ & 211 & Cfa & Humid subtropical (mild with no dry season, hot summer) \\
Paris & France (FRA) & $48.73 \mathrm{~N}$ & $2.40 \mathrm{E}$ & 96 & Cfb & Marine west coastal (warm summer, mild winter, rain all year) \\
Stockholm & Sweden (SWE) & $59.65 \mathrm{~N}$ & $17.95 \mathrm{E}$ & 61 & Dfb & Moist continental (warm summer, cold winter, no dry season) \\
Kiruna & Sweden (SWE) & $67.82 \mathrm{~N}$ & $20.33 \mathrm{E}$ & 452 & Dfc & Subarctic (cool summer, severe winter, no dry season) \\
\hline
\end{tabular}

\subsection{Synthetic dataset}

The synthetic dataset was created by running the EPSAP algorithm for 500 times for each location, with 24 buildings produced per run, totalizing 96000 buildings. The buildings were generated randomly within the building specifications and with random thermal transmittance values of the 


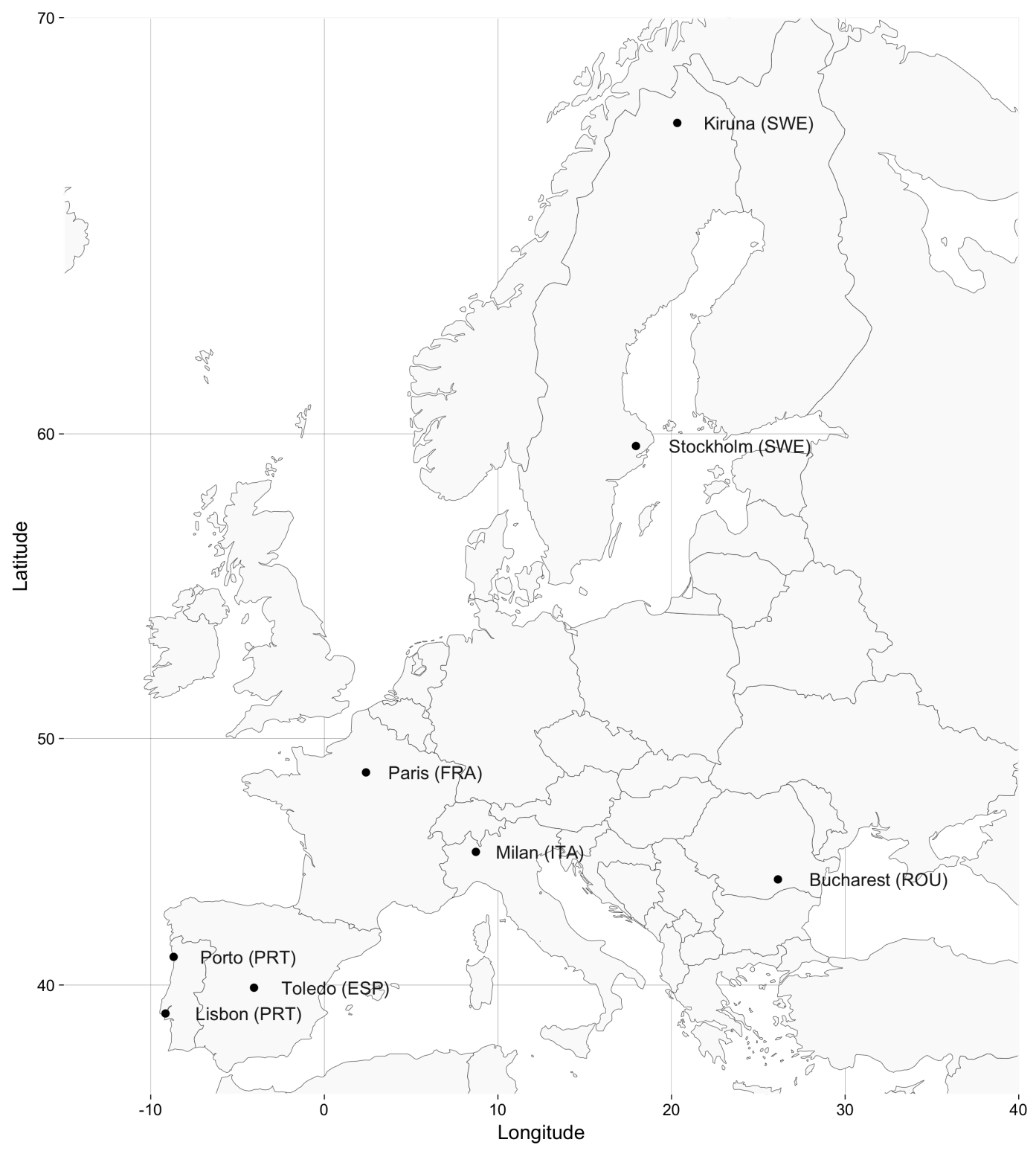

Fig. 4. European map of the selected locations.

1 exterior construction elements (roof, suspended floors, exterior wall, and windows). For each run, 2 the geometry data (number of stories, spaces, openings, etc., elements' surface areas, and volumes), 3 construction data (transparent and opaque elements' physical properties), and performance data 4 (building energy consumption, water consumption, thermal discomfort, and equipment, lighting,

5 HVAC systems energy consumption) were stored. The dataset with all locations is publicly avail6 able online in ref. [34]. Fig. 5 depict some examples of building geometry. It is possible to observe 7 the wide range of shapes, orientations, and space arrangements that comprise the synthetic dataset. 


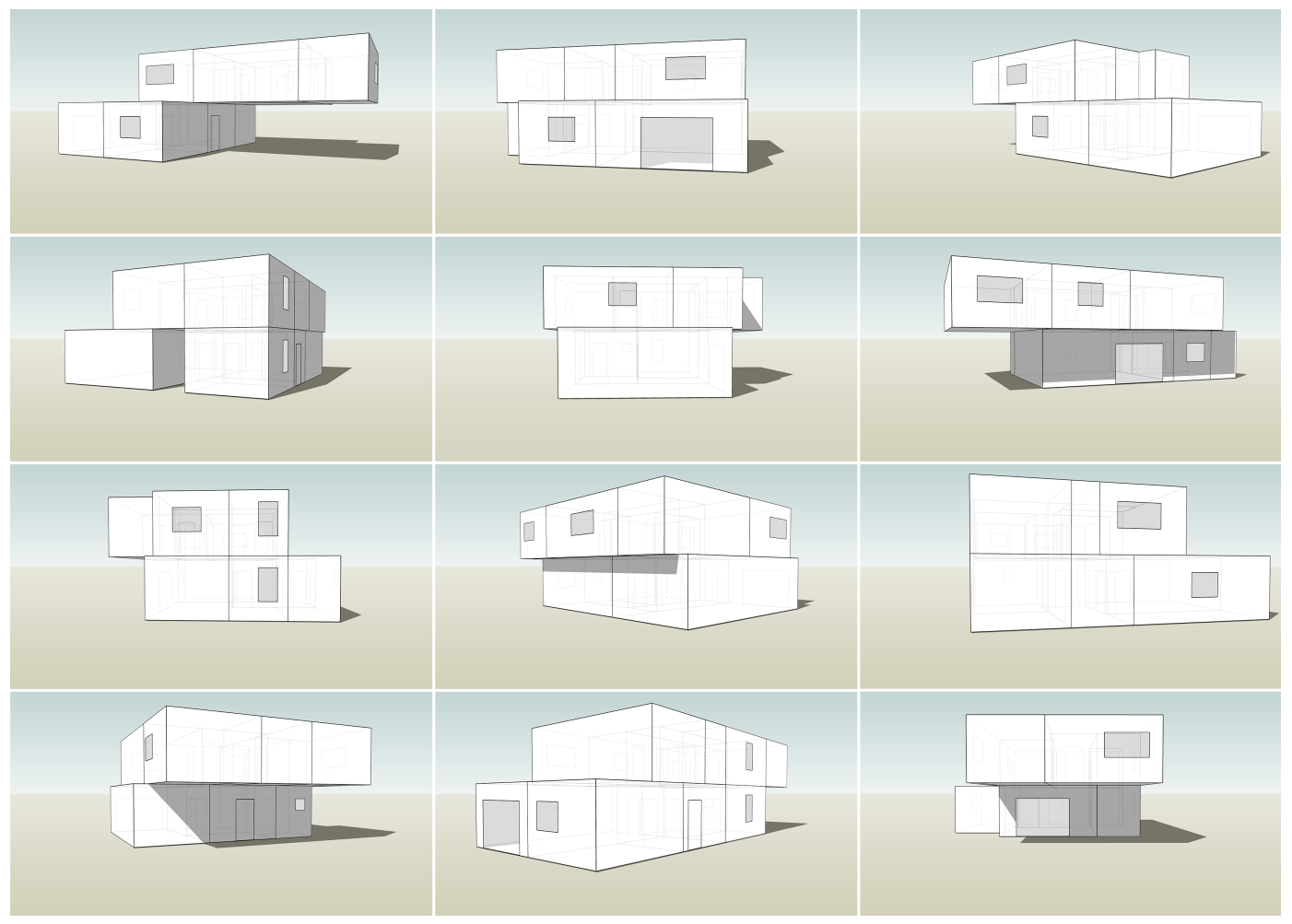

Fig. 5. Twelve examples of two-story buildings thermal zones generated by the EPSAP algorithm.

\subsection{Advantages and limitations}

The production of synthetic datasets of random building geometries with random construction thermophysical properties has some advantages and limitations. The main advantages are:

- Synthetic datasets allow to have performance information of a large number of buildings, which otherwise would be very difficult or impossible to obtain;

- Datasets of randomly generated buildings prevent biased results, as would happen if using a single building case study or a limited number of real buildings; and,

- Datasets of construction elements with randomly assigned thermal transmittance values allow to determine if there is any relation between building performance and its geometry or climate location.

Furthermore, this methodology allows:

- A comparative analysis among climate locations, independently of the buildings' geometry and construction;

- To determine ideal $U$-values of the building envelope elements for each climate location; and,

- To draw design guidelines for each climate location according to selected $U$-values of the opaque and transparent elements.

Nevertheless, some limitations should be mentioned: 
- Since the datasets were synthetically created, judicious use of the results is recommended, as these are simplified models of hypothetical real cases;

- The approach allows to determine ideal $U$-values of the envelope elements only for general use, not for specific building geometries;

- The $U$-values of the transparent and opaque elements were paired in a decreasing scale; therefore, differently paired decreasing values may give somewhat different results;

- In order to obtain comparable results, the occupation and equipment/lighting usage patterns are assumed equal for every location, which means neglecting different cultural and social backgrounds that may affect the building operation; and,

- The buildings were generated without an urban context, thus neglecting the possible contributions of solar radiation reflection or shadowing from the building surroundings.

\section{Results}

Fig. 6 presents the total, cooling, and heating energy consumption for air-conditioning boxplots for each $U$-value group per climatic location. It also depicts the distribution of buildings per group. The climatic locations are sorted ascending by latitude from top to bottom rows and the horizontal axis corresponds to each $U$-value group, ranging from $0.4 \mathrm{~W} \cdot \mathrm{m}^{-2} \cdot \mathrm{K}^{-1}$ to $6.0 \mathrm{~W} \cdot \mathrm{m}^{-2} \cdot \mathrm{K}^{-1}$, in steps of $0.2 \mathrm{~W} \cdot \mathrm{m}^{-2} \cdot \mathrm{K}^{-1}$, for transparent elements, and from $0.1 \mathrm{~W} \cdot \mathrm{m}^{-2} \cdot \mathrm{K}^{-1}$ to $1.5 \mathrm{~W} \cdot \mathrm{m}^{-2} \cdot \mathrm{K}^{-1}$, in steps of $0.05 \mathrm{~W} \cdot \mathrm{m}^{-2} \cdot \mathrm{K}^{-1}$, for opaque elements. In all locations the amplitude of energy consumption variation (i.e., the difference between the maximum and minimum energy consumption) tends to decrease as the $U$-values reduce. This happens due to the major contribution for the total energy being the heating demands, in which case building compactness, openings orientation and sizes have significant impact in improving the overall performance. However, in the South of Europe, locations such as Lisbon (PRT), Toledo (ESP), and Porto (PRT), where climate is characterized for being dry warm/hot summers and mild winters, as the $U$-values reduce the cooling energy demand increases, thus becoming the major energy consumption factor. As this happens, the energy performance worsens and the amplitude of energy consumption increases. On the other hand, due to humid mild/cold winters and hot/warm summers in Bucharest (ROU), Milan (ITA), and Paris (FRA), this effect is not noticeable and the cooling energy never inverts such tendency. Finally, in cold/severe winter and warm/cool summer climates, such as Stockholm and Kiruna (SWE), the cooling energy demand is almost neglectable. Therefore, the transposition of central Europe passive building design guidelines to the Southern countries can lead to detrimental effects, by worsening the buildings performance and, ultimately, requiring to change the design rules. 

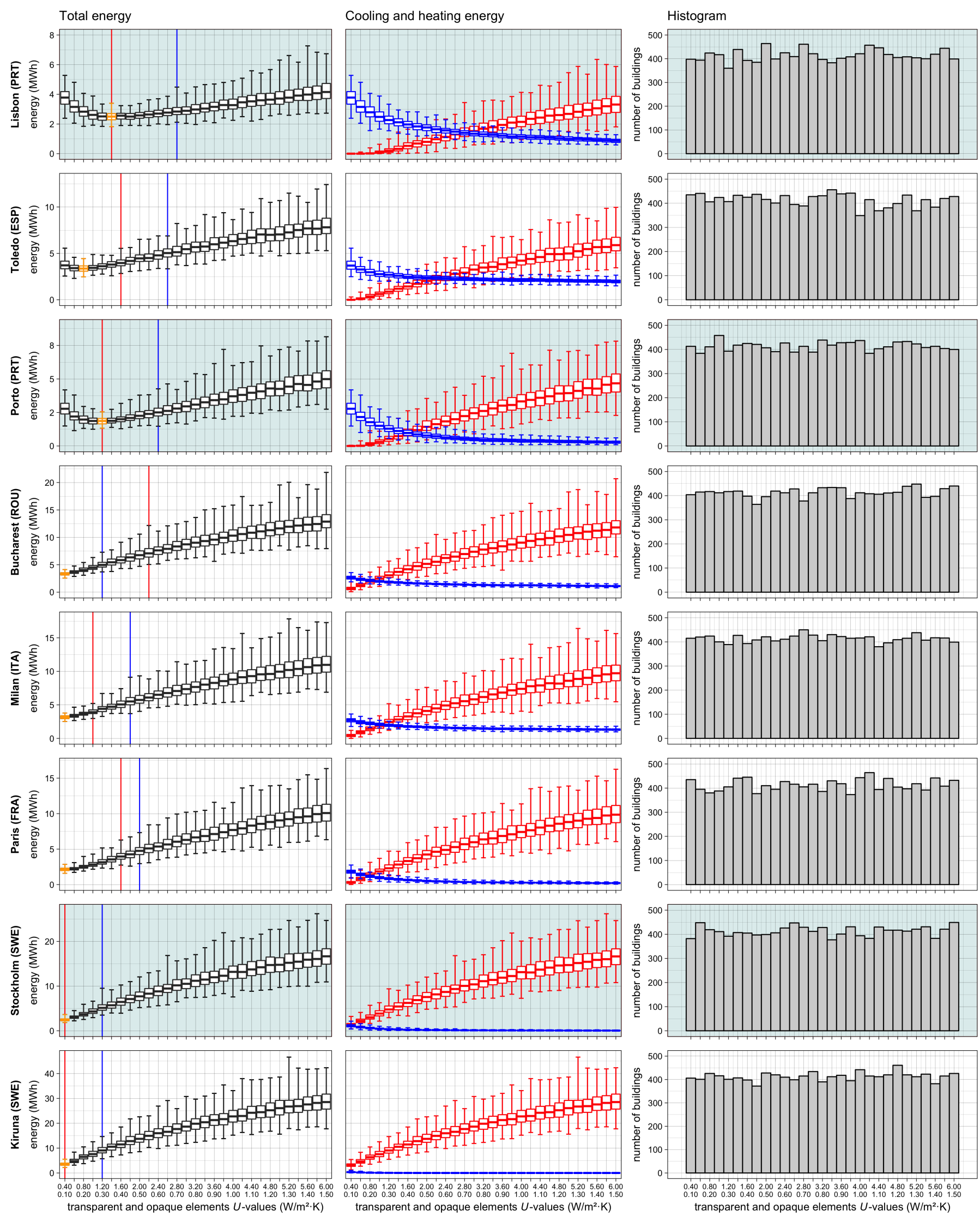

Fig. 6. Total, cooling, and heating energy consumption for air-conditioning boxplots (maximum reference $U$-values for opaque and transparent elements are marked as red and blue vertical lines, respectively) and histograms per $U$-value group per climate location. The orange boxplot in the left represents the $U$-value buildings group with the lowest average of energy consumption. Blue boxplots represent cooling energy and red boxplots the heating energy. Graphics with darker backgrounds correspond to coastal locations. 
From the perspective of energy performance, the shifting point is marked in Fig. 6 by the orange boxplot that represent the lowest total energy average of the $U$-value scale. For Lisbon (PRT), Toledo (ESP), and Porto (PRT), the more promising $U$-values from energy performance perspective are for opaque elements $0.35,0.20$, and $0.30 \mathrm{~W} \cdot \mathrm{m}^{-2} \cdot \mathrm{K}^{-1}$ and for transparent elements $1.40,0.80$, and $1.20 \mathrm{~W} \cdot \mathrm{m}^{-2} \cdot \mathrm{K}^{-1}$, respectively. For the remaining locations, the lowest $U$-value in the scale is the one with lowest total energy average. The energy performance percentage difference between the $U$-value group with the highest and the one with the lowest total energy average is $41 \%$ (Lisbon - PRT), $58 \%$ (Toledo - ESP), $63 \%$ (Porto - PRT), $74 \%$ (Bucharest - ROU), $72 \%$ (Milan - ITA), $79 \%$ (Paris - FRA), $85 \%$ (Stockholm - SWE), and $88 \%$ (Kiruna - SWE); therefore, the northern and colder locations are the ones that benefit the most from the decrease in the thermal transmittance.

It should be remarked that, for static comparison purposes (identical profiles), overnight ventilation was not adopted for any of the locations. However, in reality, building occupants in southern locations could make use of this technique to dissipate excess heat during the summer period. In the case of this study, the free cooling or overnight ventilation would slightly decrease the cooling energy consumption for the entire $U$-values range. This would slightly modify the total energy curve in Fig. 6 as well, and, therefore, the group of $U$-values with the lowest energy consumption average.

The continuous lowering of thermal transmittance values in Southern countries, such as Portugal and Spain, imposed by building regulation is leading to a shift in the building design paradigm from heating to cooling demands. However, the impacts in the building geometry were not yet fully studied. Figs. 77 and 8 show, in the left graphic, the coefficient of determination for the correlation between some geometry-based indexes $\left(V\right.$ - building volume, $R C$ - relative compactness, $C_{f}-$ shape coefficient, $W F R$ - window-to-floor ratio, $W W R$ - window to wall ratio, $W S R$ - windowto-exterior surface ratio, and WSR for orientation North, East, South, and West) and the $U$-value group for each climate region. In the right graphic, it is depicted for each sample pair indexgroup the calculated probability that did not reject the null hypothesis $\left(\mathrm{H}_{0}\right)$ for a threshold of $p$-value $\geq 0.01$. The green cells represent negative correlation (i.e., the increase of such index decreases the energy consumption) and red cells depict positive correlation - the increase of both the index and energy consumption. The correlation scale (coefficient of determination, $\mathrm{R}^{2}$ ) was considered having the intervals $[0,0.2[$ for very weak, $[0.2,0.4[$ for weak, $[0.4,0.6[$ for moderate, $[0.6,0.8[$ for strong, and $[0.8,1]$ for very strong. 


\section{Correlation}

Coefficient of determination

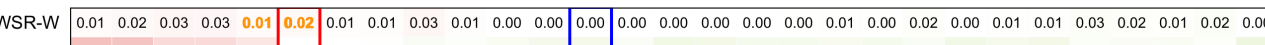

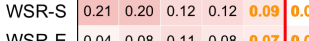

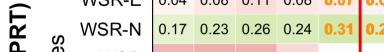

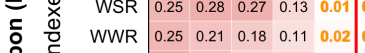

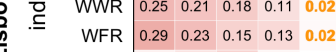

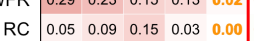

Cf $\begin{array}{lllll}0.00 & 0.01 & 0.04 & 0.00 & 0.01\end{array}$

$\begin{array}{lllllll} & 0\end{array}$

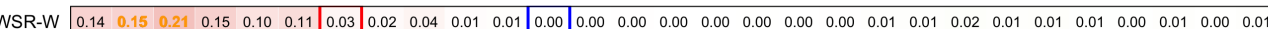

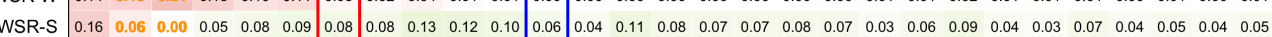

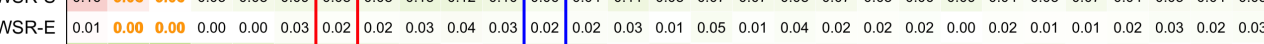

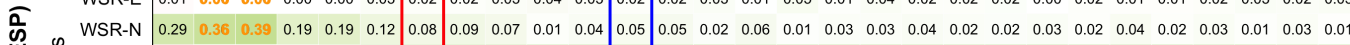

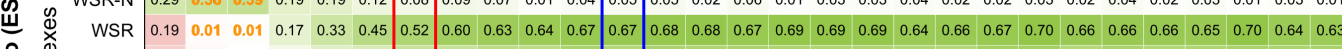

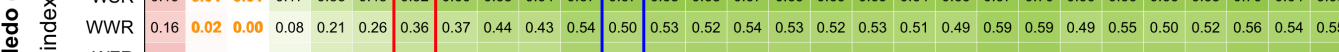

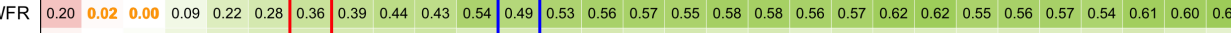

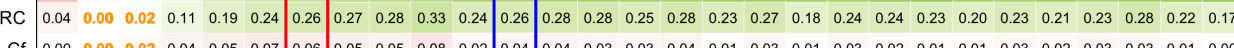

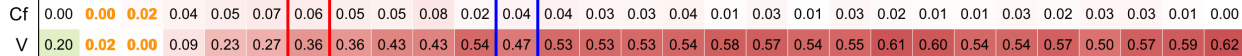
WSR-W \begin{tabular}{llll|l|lllll|l|llllllllllllllllll}
0.06 & 0.07 & 0.15 & 0.15 & 0.09 & 0.06 & 0.00 & 0.03 & 0.00 & 0.00 & 0.00 & 0.00 & 0.00 & 0.00 & 0.00 & 0.01 & 0.02 & 0.00 & 0.04 & 0.02 & 0.01 & 0.01 & 0.02 & 0.02 & 0.01 & 0.01 & 0.02 & 0.01 & 0.02
\end{tabular}

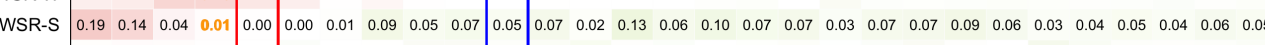

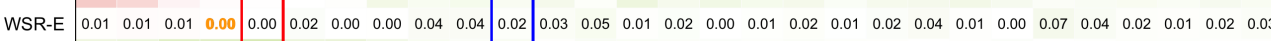

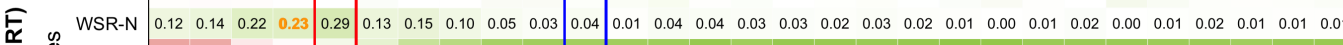

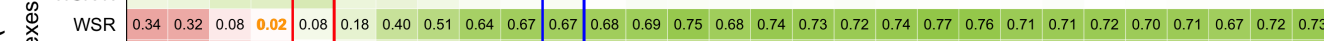

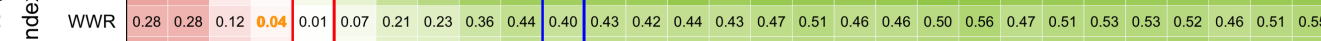
WFR \begin{tabular}{lllllllllll|lllllllllllllllllllll}
0.31 & 0.30 & 0.14 & 0.05 & 0.01 & 0.05 & 0.20 & 0.23 & 0.33 & 0.44 & 0.39 & 0.46 & 0.45 & 0.47 & 0.45 & 0.48 & 0.51 & 0.49 & 0.49 & 0.54 & 0.57 & 0.50 & 0.54 & 0.56 & 0.57 & 0.60 & 0.52 & 0.54 & 0.57
\end{tabular}

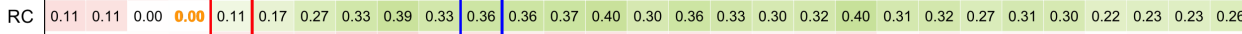

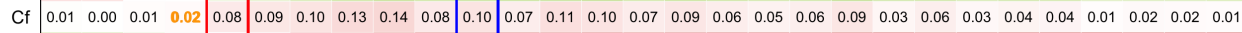

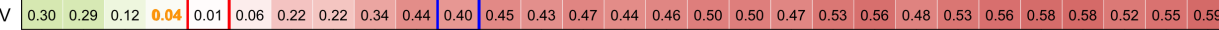

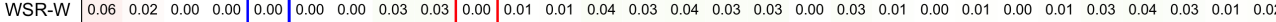

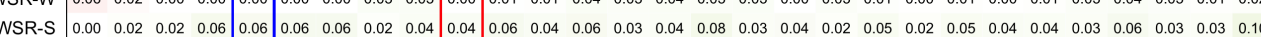

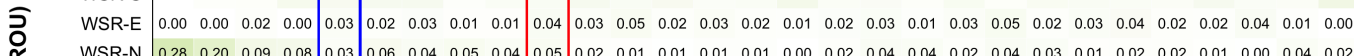

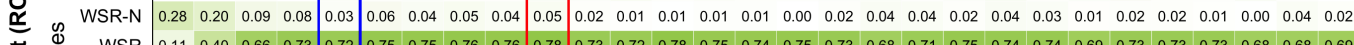

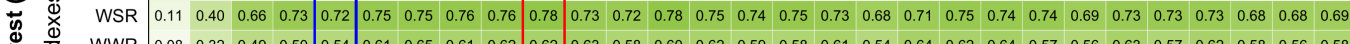

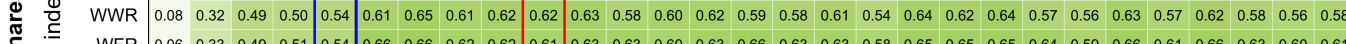

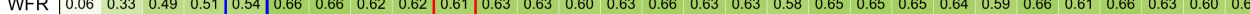

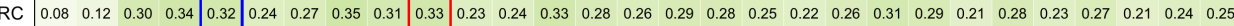

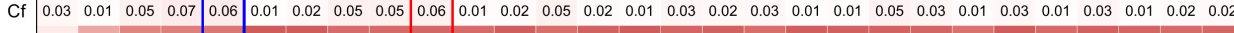

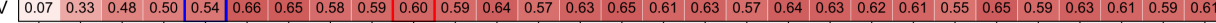

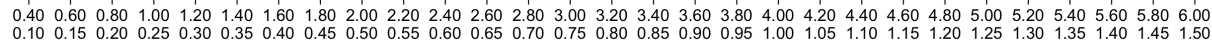
transparent and opaque elements $U$-values $\left(\mathrm{W} / \mathrm{m}^{2} \cdot \mathrm{K}\right)$
Calculated probability

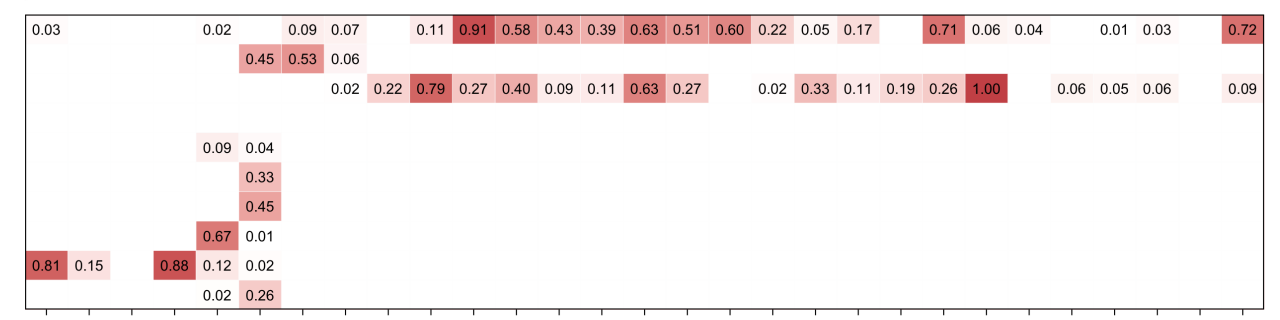

\begin{tabular}{|c|c|c|c|c|c|c|c|c|}
\hline & 0.11 & 0.490 & 0.33 & 0.27 & $\begin{array}{lll}0.06 & 0.01 & 0.0\end{array}$ & 0.03 & $0.15 \mathrm{c}$ & $\begin{array}{llll}0.10 & 0.34 & 0.07\end{array}$ \\
\hline & & & & & & & & \\
\hline \multirow{2}{*}{ 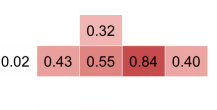 } & & 0.10 & 0.02 & & 0.44 & 0.02 & 0.04 & \\
\hline & 0.01 & & & & & & 0.01 & 0.02 \\
\hline \multicolumn{9}{|l|}{$\begin{array}{cr}0.01 & 0.02 \\
& 0.55\end{array}$} \\
\hline \multicolumn{9}{|l|}{0.48} \\
\hline 0.54 & & & & & & & & \\
\hline 0.57 & & & 0.04 & 0.18 & $\begin{array}{llll}0.02 & 0.04 & 0.0\end{array}$ & & 0.01 & $0.02 \quad 0.90$ \\
\hline 0.20 & & & & & & & & \\
\hline
\end{tabular}

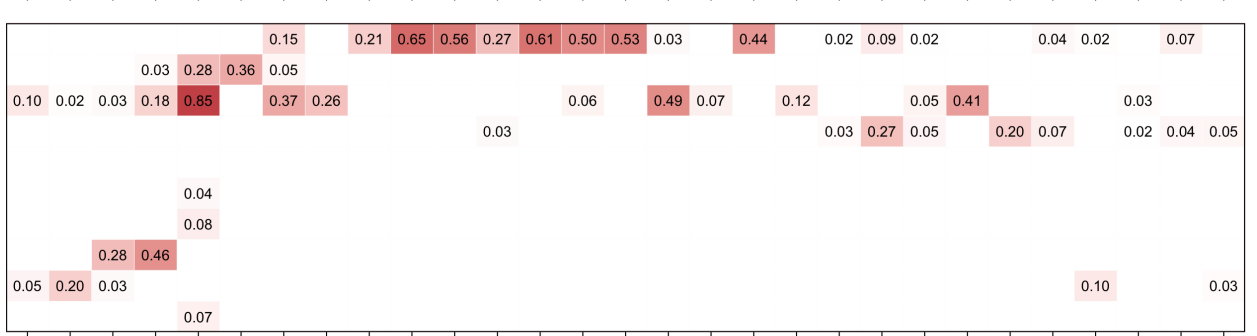

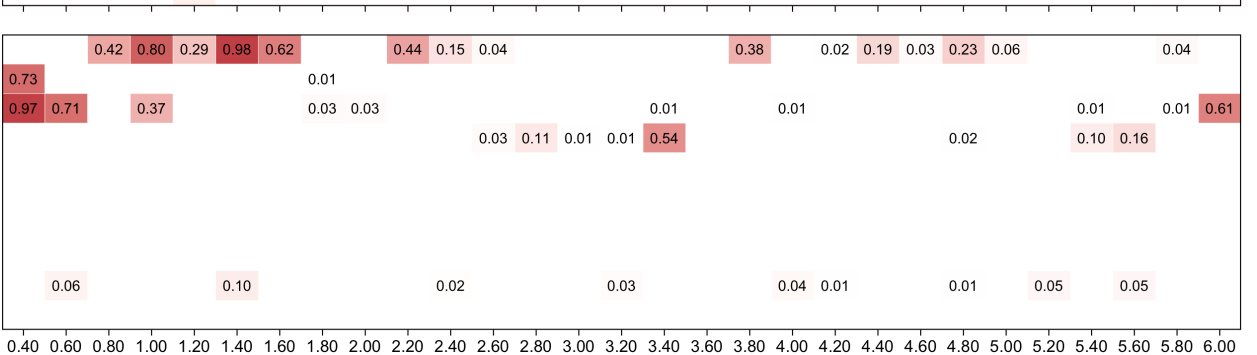

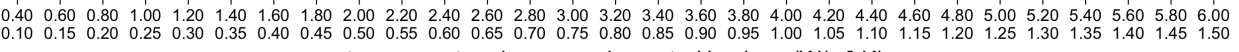
transparent and opaque elements $U$-values $\left(\mathrm{W} / \mathrm{m}^{2} \cdot \mathrm{K}\right)$

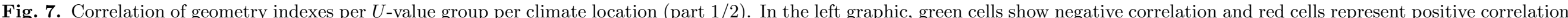

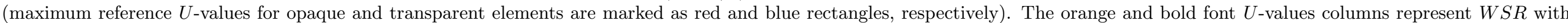
$\mathrm{R}^{2} \leq 0.02$. On the right graphic, red cells indicate subgroups having $p$-value above or equal to the threshold of 0.01 


\section{Correlation}

Coefficient of determination

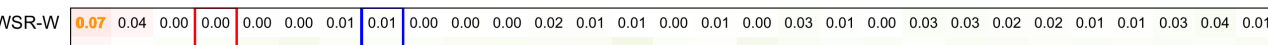
WSR-S \begin{tabular}{llll|l|lll|l|llllllllllllllllllllllll}
0.03 & 0.01 & 0.03 & 0.03 & 0.05 & 0.07 & 0.03 & 0.03 & 0.03 & 0.04 & 0.05 & 0.04 & 0.05 & 0.09 & 0.03 & 0.02 & 0.07 & 0.05 & 0.02 & 0.04 & 0.02 & 0.04 & 0.04 & 0.03 & 0.03 & 0.03 & 0.03 & 0.03 & 0.05
\end{tabular}

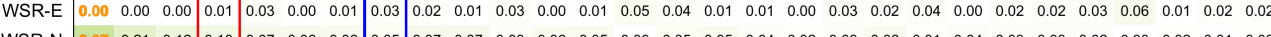
象 WSR-N

ᄃ ब

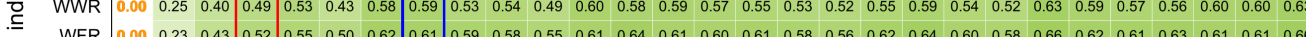

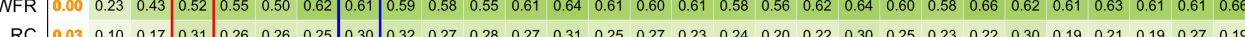

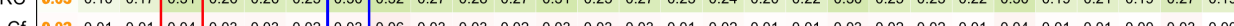

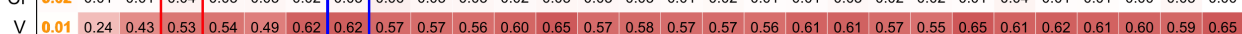

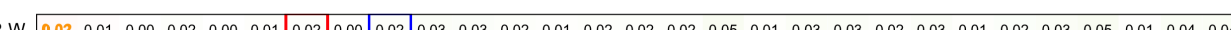
0.030 .050 .010 .040 .04

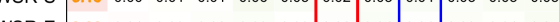

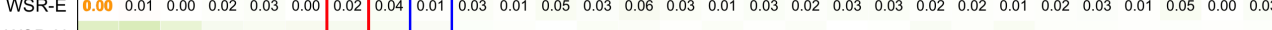

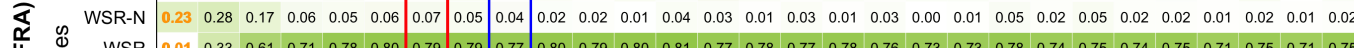
$\begin{array}{lllllllllllllllllllll} & 0.74\end{array}$

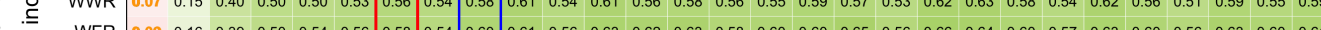

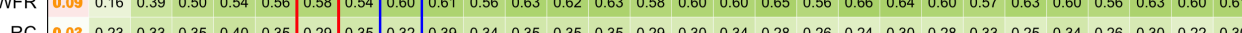
RC \begin{tabular}{lllllll|l|l|lllllllllllllllllllllllllll}
0.03 & 0.23 & 0.33 & 0.35 & 0.40 & 0.35 & 0.29 & 0.35 & 0.32 & 0.39 & 0.34 & 0.35 & 0.35 & 0.35 & 0.29 & 0.30 & 0.34 & 0.28 & 0.26 & 0.24 & 0.30 & 0.28 & 0.33 & 0.25 & 0.34 & 0.26 & 0.30 & 0.22 & 0.30
\end{tabular} Cf \begin{tabular}{lllllllll|l|l|lllllllllllllllllllll}
0.08 & 0.08 & 0.08 & 0.08 & 0.09 & 0.05 & 0.03 & 0.07 & 0.04 & 0.07 & 0.06 & 0.05 & 0.04 & 0.06 & 0.03 & 0.04 & 0.05 & 0.03 & 0.02 & 0.01 & 0.03 & 0.03 & 0.06 & 0.02 & 0.07 & 0.03 & 0.04 & 0.02 & 0.03
\end{tabular}

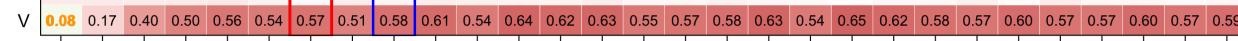

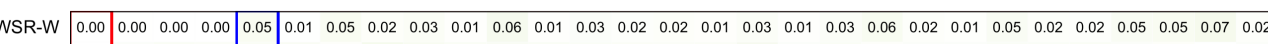

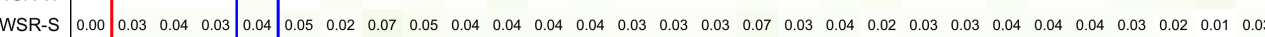

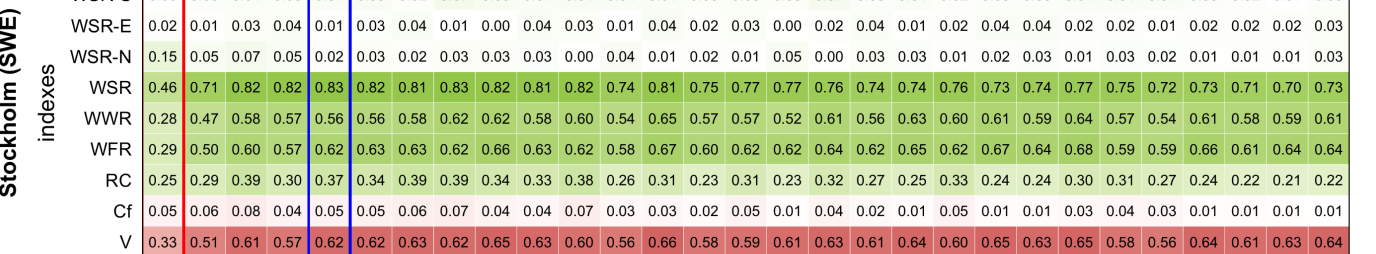

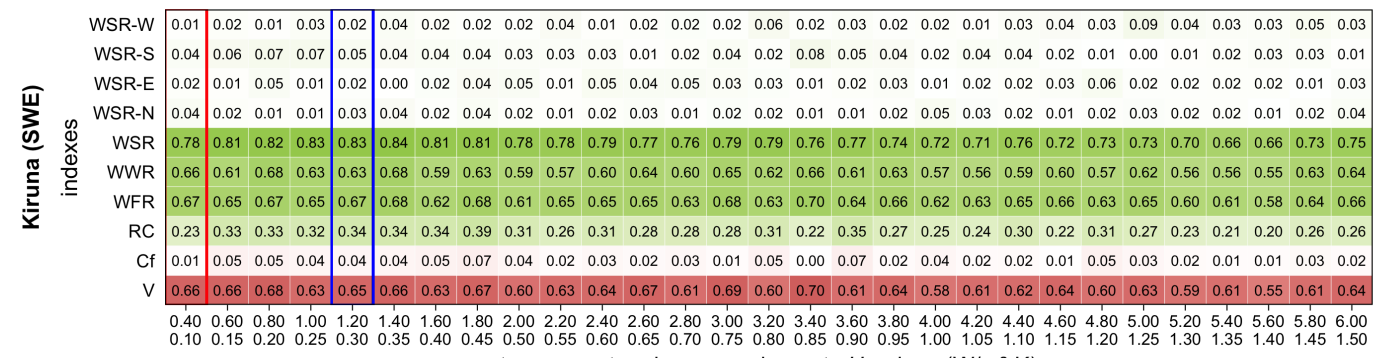
transparent and opaque elements $U$-values $\left(\mathrm{W} / \mathrm{m}^{2} \cdot \mathrm{K}\right)$
Calculated probability

$p$-value

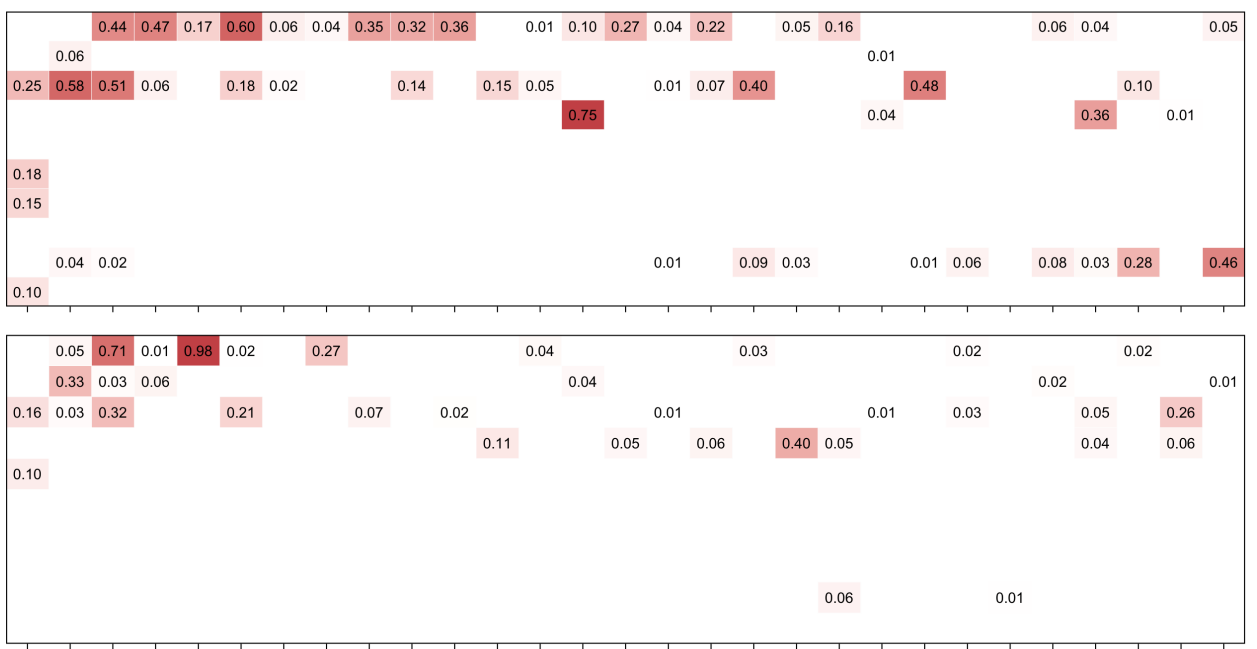

\begin{tabular}{|c|c|c|c|c|c|c|c|c|c|c|c|c|}
\hline \begin{tabular}{|llll}
0.56 & 0.18 & 0.71 & 0.47 \\
\end{tabular} & 0. & 0.10 & & 0.05 & 0.03 & & & 0.04 & 0.07 & & & \\
\hline 0.41 & & & & & & & & & & & & 0.09 \\
\hline \multirow[t]{3}{*}{$0.02 \quad 0.01$} & 0.02 & & 0.140 .28 & & 0.10 & & & 0.05 & & & & \\
\hline & & & & 0.1 & & 0.04 & 0.18 & 0.0 & & 0.04 & $\begin{array}{lll}0.06 & 0.04\end{array}$ & 0.03 \\
\hline & & & & & & & & 0.02 & $0.02 \quad 0.02$ & & $\begin{array}{ll}0.03 & 0.02\end{array}$ & $\begin{array}{lll}0.09 & 0.13\end{array}$ \\
\hline
\end{tabular}

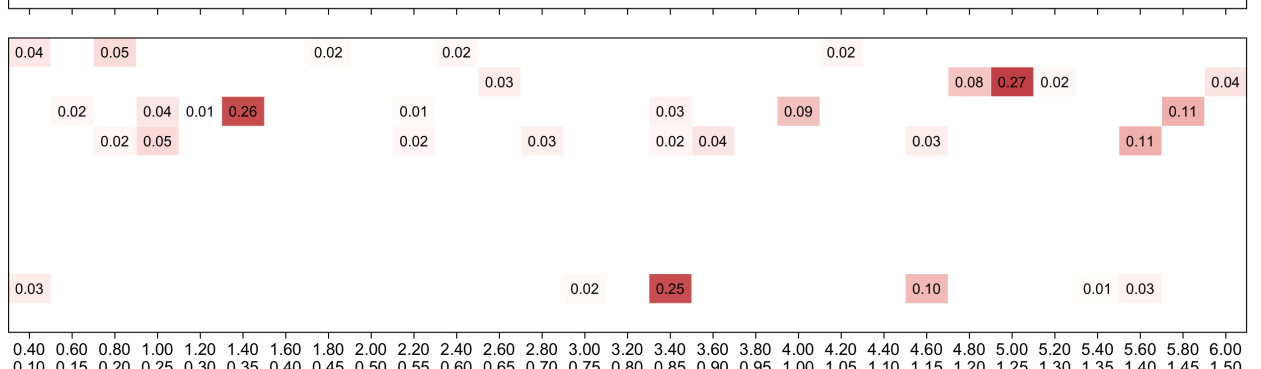

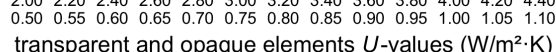

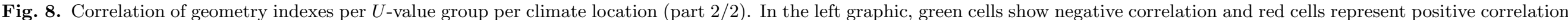

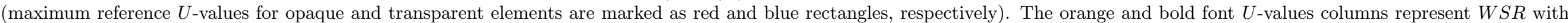
$\mathrm{R}^{2} \leq 0.02$. On the right graphic, red cells indicate subgroups having $p$-value above or equal to the threshold of 0.01 
As depicted in Figs. 7 and 8 , the building volume $(V)$ has moderate positive correlation with energy consumption for higher $U$-values. In other words, bigger buildings are unable to retain heat and the bigger the volume the more energy is required to maintain the indoor environment within the thermal comfort limits. As the $U$-values decrease, the correlation weakens, reaching almost none for Lisbon (PRT), Toledo (ESP), Porto (PRT), Bucharest (ROU), Milan (ITA), and Paris (FRA). In the case of the locations in the Iberian Peninsula, the building volume even becomes negatively correlated, thus, due to overheating, the bigger the building the less energy it consumes.

Looking at the columns with orange values in Figs. 7 and 8 , which correspond to the locations where the $W S R$ has a $\mathrm{R}^{2} \leq 0.02$ (arbitrary value for determining no correlation)-found only for Lisbon (PRT), Toledo (ESP), Porto (PRT), Milan (ITA), and Paris (FRA) - , they mark the shift point from the current geometric design guidelines - small and compact building shapes (positive correlation of $V$ and negative correlation of $R C$ ) and large windows (negative correlation for $W S R$, $W W R$, and $W F R$ - to another set of guidelines - small windows facing South and West/East (positive correlation for $W S R-W$ and $W S R-S$ ), large windows facing North (negative correlation for $W S R-N$ ), large and less compact buildings (negative correlation of $V$ and positive correlation of $R C$ ). Moreover, those referred columns define themselves a set of specific design orientations, where the window size does not have significant impact (none or very weak correlation for $W S R$, $W F R$, and $W F R$ ), neither the building size and compactness (none or very weak correlation for $V$ and $R C$ ), while windows facing North contribute to improve the building performance (weak negative correlation for $W S R-N)$. Exclusively for Porto (PRT) and Toledo (ESP), the windows facing West (very weak positive correlation for $W S R-W$ ) may increase the energy consumption.

Relatively to the building form indexes, the shape coefficient $\left(C_{f}\right)$ does not present any kind of correlation for any of the $U$-values and in any of the locations. This may be justified with the volume variation of the generated buildings. However, when considering the relative compactness $(R C)$, the correlation goes from weak negative to none or very weak, thus meaning that the building compactness tends to decrease the energy consumption. In the southern countries of Europe, for very low $U$-values, the $R C$ inverts its influence presenting very weak positive correlation (compactness slightly increases energy consumption).

Regarding the influence of window indexes (WFR,WWR, and $W S R$ ) on energy consumption, all locations present moderate to strong negative correlations for higher $U$-values, that tend to decrease with decreasing $U$-values. Hence, for high $U$-values, the glazing areas improve the buildings performance by reducing the heating needs. For very low $U$-values, the windows' dimensions no longer affect the building performance, except for Bucharest (ROU), Stockholm (SWE), and Kiruna (SWE). In the cases of Lisbon (PRT), Porto (PRT), and Toledo (ESP), where the cooling demands increase significantly for very low $U$-values, the window indexes show a weak positive 
correlation, i.e., glazing areas have a detrimental influence on the buildings' energy consumption.

Besides, for these three locations, the influence of windows orientation must be taken into account:

for low $U$-values, the $W S R$ - $N$ present very weak and weak negative correlation, thus favorable for energy performance; for very low $U$-values, $W S R$-S has very weak positive correlation. While a very weak positive correlation of $W S R$-W is observed in Toledo (ESP) and Porto (PRT), WSR$E$ shows a very weak positive correlation in Lisbon (PRT). Also noticeable is the fact that the point of none or very weak correlation in Figs. 7 and 8 , especially for the window-based indexes, corresponds to the point of lower energy consumption in Fig. 6 .

\section{Discussion}

According to Fig. 6, which depicts the maximum reference $U$-values for transparent (vertical blue line) and opaque elements (the lowest value of all opaque envelope elements is marked as red vertical line) obtained from each country legislation or from ref. [35, the $U$-values can be further reduced, as the buildings performance may benefit from lower thermal transmittance. However, for the cases of Lisbon (PRT), Toledo (ESP), and Porto (PRT), there is not much more space to improve, as overheating may significantly increase. As depicted in Figs. 7 and 8 and considering the reference $U$-values for transparent (marked as blue rectangle) and opaque (the lowest value of all opaque envelope elements is marked as red rectangle) elements, it is possible to understand that the influence of glazing areas and building shape have already changed for Lisbon (PRT), Toledo (ESP), and Porto (PRT) and, if the thermal transmittances get lower for Milan (ITA) and Stockholm (SWE), the design guidelines must also change. On the other hand, for Bucharest (ROU), Paris (FRA) and Kiruna (SWE), $U$-values can get lower without compromising current design guidelines: in the cases of Bucharest (ROU) and Paris (FRA), the reference $U$-values are still high in comparison with those of other climate regions with similar latitudes; as for Kiruna (SWE), the indicators do not change significantly in the studied $U$-value scale interval due to the extreme cold weather.

The results of this study show that a clear relation between the thermal transmittance of the construction elements and the buildings geometry does exist, which leads to the necessity of rethinking the design guidelines. As $U$-values decrease in scenarios of major heating demands, geometric variables (e.g., windows size and orientation, and buildings compactness) become less important. Therefore, the energy performance of buildings with different forms becomes equivalent, with a lower performance amplitude. This means an increased freedom for the designer to explore less compact shapes and larger glazing areas. Contrarily, in southern regions where cooling needs increase due to warmer climates, decreasing $U$-values lead to higher energy consumptions, and the influence of building geometry becomes important and must be analyzed in detail: (i) the 
size of South and West facing windows is a detrimental factor for the energy performance; (ii) North facing windows have larger sizes, while South and West facing windows should have small sizes; (iii) the building shape should also be non-compact to facilitate the heat release through the larger exterior surface areas. However, these instructions for warmer climates do not prevent low $U$-value solutions from leading to worse performances than constructions with higher thermal transmittances. In other words, there is an adequate $U$-value interval that combines the best performance and the geometry freedom that designers desire. Moreover, the scale of $U$-values per climate region can be very helpful for building practitioners to determine the most adequate geometry guidelines for a pre-determined $U$-values. Depending on the position in the $U$-value scale, the designer can expect the impact of the windows size and orientation and of the building shape (more or less compact). The findings are the following:

- As the $U$-values get lower, the buildings energy consumption and the group energy performance amplitude decrease, meaning that building practitioners are freer to explore other building forms;

- In southern countries, for very low $U$-values, the tendency reverses: the average energy consumption and the performance amplitude increase, meaning that the building geometry starts to have influence again, however due to different reasons;

- In warm and moderate climates, due to very small cooling demands, the influence of buildings shape and windows design have lower impact for very low $U$-values;

- In cold and subarctic climates, for very low $U$-values, besides not occurring significant cooling needs, the influence of buildings shape and windows design have a smaller impact;

- Ideal $U$-values increase the buildings robustness, as these are less influenced by the geometry variables (building shapes, openings dimensions and orientation have lower impact). However, global warming may disrupt this balance by shifting the ideal thermal transmittance to higher values and, consequently, increasing the energy consumption due to unpredicted cooling needs. In future dwellings, new habits with higher internal gains may also contribute to disrupt this balance; and lastly,

- When the energy consumption is at the lowest in the $U$-values scale, geometry-based indexes present none or very weak correlations, thus meaning that the building performance improves and building designers may explore alternative building forms and window dimensions.

\section{Conclusion}

In this study, 96000 geometries were randomly generated, with random $U$-values for roofs, exterior walls, suspended floors, exterior doors, and windows. Considering eight climate locations 
in Europe, the energy performance of those buildings was evaluated, and the range of annual energy consumption and its correlation with six geometry indexes were determined for each pair of $U$-values of the opaque and transparent elements. The statistical analysis of this large synthetic dataset allowed to determine the impact of the $U$-value variation in the energy performance and building geometry. Therefore, the results are not related to a specific building geometry solution but rather to a general trend observed from a great number of buildings analyzed. The impact of $U$-values is presented in scale of values, thus allowing building practitioners to deduce the most adequate design actions for each specific value of thermal transmittance for transparent and opaque elements. Moreover, this methodology has potential applications, such as to improve the search speed of optimization procedures that seek to find the best construction solution by using the most promising $U$-values for a certain climate region, for instance as starting indicative values to be used in early stages of building design, when the building geometry is still vague or not defined yet.

The main results showed that the $U$-values variation has implications in the current building guidelines (building shape compactness and windows dimensions and orientations), depending on the climate region. Some of the locations even present three sets of design guidelines, such as Lisbon (PRT), Toledo (ESP), and Porto (PRT), and others two sets in extreme low $U$-values, such as Milan (ITA) and Paris (FRA), due to the impact of cooling demand in the building geometry. For all climate regions, lowering the $U$-values increase the building robustness to geometry variations and reduces the energy consumption for air-conditioning up to a point where the overheating inverts this tendency. Moreover, the results show that for warmer climates, very low $U$-values can have a pernicious effect on the energy performance, by making the building more susceptible to the geometry choices. Therefore, these results are themselves a useful instrument for the building practitioners in the early stages of building design.

For future work, it would be important to study the impact of low $U$-values in other climatic regions and building scenarios: single-story and high-rise buildings; non-residential buildings that have daytime occupancy and great internal gains; low inertia buildings; and, buildings with shading mechanisms (to understand if high efficient artificial lighting may lead to shading mechanisms being permanently activated).

\section{Acknowledgements} University of Coimbra (UC).

Funding: This work has been financed by the Portuguese Foundation for Science and Technology (FCT) and by the European Regional Development Fund (FEDER) through COMPETE 2020 - Operational Program for Competitiveness and Internationalization (POCI) in the framework of 
the research projects PCMs4Buildings (PTDC/EMS-ENE/6079/2014 and POCI-01-0145-FEDER2 016750) and Ren4EEnIEQ (PTDC/EMS-ENE/3238/2014, POCI-01-0145-FEDER-016760, and LISBOA3 01-0145-FEDER-016760). Eugénio Rodrigues acknowledges the support provided by the FCT, 4 under Postdoc grant SFRH/BPD/99668/2014.

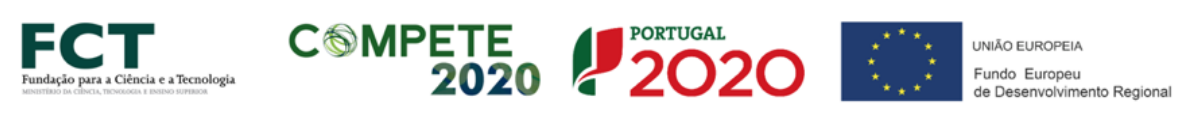

Declarations of interest: none.

\section{References}

[1] N. Soares, J. Bastos, L. Dias Pereira, A. Soares, A. R. Amaral, E. Asadi, E. Rodrigues, F. B. Lamas, H. Monteiro, M. A. Lopes, A. R. Gaspar, A review on current advances in the energy and environmental performance of buildings towards a more sustainable built environment, Renewable and Sustainable Energy Reviews 77 (February 2016) (2017) 845-860, ISSN 13640321, doi:10.1016/j.rser.2017.04.027

[2] L. Vanhoutteghem, S. Svendsen, Modern insulation requirements change the rules of architectural design in low-energy homes, Renewable Energy 72 (2014) 301-310, ISSN 09601481, doi:10.1016/j.renene.2014.07.005

[3] A. Figueiredo, J. Kämpf, R. Vicente, Passive house optimization for Portugal: Overheating evaluation and energy performance, Energy and Buildings 118 (2016) 181-196, ISSN 03787788, doi:10.1016/j.enbuild. 2016.02.034. URL http://dx.doi.org/10.1016/j.enbuild.2016.02.034http://linkinghub.elsevier.com/ retrieve/pii/S0378778816300925.

[4] L. Vanhoutteghem, G. C. J. Skarning, C. A. Hviid, S. Svendsen, Impact of façade window design on energy, daylighting and thermal comfort in nearly zero-energy houses, Energy and Buildings 102 (2015) 149-156, ISSN 03787788, doi:10.1016/j.enbuild.2015.05.018

[5] S. Attia, P. Eleftheriou, F. Xeni, R. Morlot, C. Ménézo, V. Kostopoulos, M. Betsi, I. Kalaitzoglou, L. Pagliano, M. Cellura, M. Almeida, M. Ferreira, T. Baracu, V. Badescu, R. Crutescu, J. M. Hidalgo-Betanzos, Overview and future challenges of nearly zero energy buildings (nZEB) design in Southern Europe, Energy and Buildings 155 (2017) (2017) 439-458, ISSN 03787788, doi:10.1016/j.enbuild.2017.09.043

[6] F. Goia, Search for the optimal window-to-wall ratio in office buildings in different European climates and the implications on total energy saving potential, Solar Energy 132 (2016) 467-492, ISSN 0038092X, doi:10.1016/j. solener.2016.03.031

[7] P. Ma, L.-S. Wang, N. Guo, Maximum window-to-wall ratio of a thermally autonomous building as a function of envelope U-value and ambient temperature amplitude, Applied Energy 146 (2015) 84-91, ISSN 03062619, doi:10.1016/j.apenergy.2015.01.103

[8] E. O. Assem, Correlating thermal transmittance limits of walls and roofs to orientation and solar absorption, Energy and Buildings 43 (11) (2011) 3173-3180, ISSN 03787788, doi:10.1016/j.enbuild.2011.08.015

[9] A. R. Amaral, E. Rodrigues, A. R. Gaspar, Á. Gomes, A thermal performance parametric study of window type, orientation, size and shadowing effect, Sustainable Cities and Society 26 (2016) 456-465, doi:10.1016/j. scs.2016.05.014

[10] E. Rodrigues, A. R. Amaral, A. R. Gaspar, Á. Gomes, How reliable are geometry-based building indices as thermal performance indicators?, Energy Conversion and Management 101 (2015) 561-578, ISSN 01968904, doi:10.1016/j.enconman.2015.06.011 
[11] F. Stazi, C. Bonfigli, E. Tomassoni, C. Di Perna, P. Munafò, The effect of high thermal insulation on high thermal mass: Is the dynamic behaviour of traditional envelopes in Mediterranean climates still possible?, Energy and Buildings 88 (2015) 367-383, ISSN 03787788, doi:10.1016/j.enbuild.2014.11.056

[12] M. Kimber, W. W. Clark, L. Schaefer, Conceptual analysis and design of a partitioned multifunctional smart insulation, Applied Energy 114 (2014) 310-319, ISSN 03062619, doi:10.1016/j.apenergy.2013.09.067

[13] T. Pflug, N. Nestle, T. E. Kuhn, M. Siroux, C. Maurer, Modeling of facade elements with switchable U-value, Energy and Buildings 164 (2018) 1-13, ISSN 03787788, doi:10.1016/j.enbuild.2017.12.044.

[14] S. Craig, J. Grinham, Breathing walls: The design of porous materials for heat exchange and decentralized ventilation, Energy and Buildings 149 (2017) 246-259, ISSN 03787788, doi:10.1016/j.enbuild.2017.05.036.

[15] E. Rodrigues, A. R. Gaspar, Á. Gomes, An approach to the multi-level space allocation problem in architecture using a hybrid evolutionary technique, Automation in Construction 35 (2013) 482-498, ISSN 09265805, doi: 10.1016/j.autcon.2013.06.005.

[16] E. Rodrigues, A. R. Gaspar, Á. Gomes, An evolutionary strategy enhanced with a local search technique for the space allocation problem in architecture, Part 2: Validation and performance tests, Computer-Aided Design 45 (5) (2013) 898-910, ISSN 00104485, doi:10.1016/j.cad.2013.01.003

[17] E. Rodrigues, A. R. Gaspar, Á. Gomes, An evolutionary strategy enhanced with a local search technique for the space allocation problem in architecture, Part 1: Methodology, Computer-Aided Design 45 (5) (2013) 887-897, ISSN 00104485, doi:10.1016/j.cad.2013.01.001.

[18] E. Rodrigues, A. R. Gaspar, Á. Gomes, Improving thermal performance of automatically generated floor plans using a geometric variable sequential optimization procedure, Applied Energy 132 (2014) 200-215, ISSN 03062619, doi:10.1016/j.apenergy.2014.06.068

[19] E. Rodrigues, A. R. Gaspar, Á. Gomes, Automated approach for design generation and thermal assessment of alternative floor plans, Energy and Buildings 81 (2014) 170-181, ISSN 03787788, doi:10.1016/j.enbuild.2014.06. 016

[20] P. Depecker, C. Menezo, J. Virgone, S. Lepers, Design of buildings shape and energetic consumption, Building and Environment 36 (5) (2001) 627-635, ISSN 03601323, doi:10.1016/S0360-1323(00)00044-5

[21] W. Pessenlehner, A. Mahdavi, Building morphology, transparence, and energy performance, in: Procedings of Building Simulation 2003, Eindhoven, Netherlands, 1025-1032, URL http://www.ibpsa.org/proceedings/ BS2003/BS03_1025_1032.pdf, 2003.

[22] U. T. Aksoy, M. Inalli, Impacts of some building passive design parameters on heating demand for a cold region, Building and Environment 41 (12) (2006) 1742-1754, ISSN 03601323, doi:10.1016/j.buildenv.2005.07.011

[23] M.-L. Persson, A. Roos, M. Wall, Influence of window size on the energy balance of low energy houses, Energy and Buildings 38 (3) (2006) 181-188, ISSN 03787788, doi:10.1016/j.enbuild.2005.05.006

[24] a. Stegou-Sagia, K. Antonopoulos, C. Angelopoulou, G. Kotsiovelos, The impact of glazing on energy consumption and comfort, Energy Conversion and Management 48 (11) (2007) 2844-2852, ISSN 01968904, doi: 10.1016/j.enconman.2007.07.005

[25] R. Ourghi, A. Al-Anzi, M. Krarti, A simplified analysis method to predict the impact of shape on annual energy use for office buildings, Energy Conversion and Management 48 (1) (2007) 300-305, ISSN 01968904, doi:10.1016/j.enconman.2006.04.011.

[26] K. Hassouneh, A. Alshboul, A. Al-Salaymeh, Influence of windows on the energy balance of apartment buildings in Amman, Energy Conversion and Management 51 (8) (2010) 1583-1591, ISSN 01968904, doi: 10.1016/j.enconman.2009.08.037

[27] S. G. Yong, J. H. Kim, Y. Gim, J. Kim, J. Cho, H. Hong, Y. J. Baik, J. Koo, Impacts of building envelope 
design factors upon energy loads and their optimization in US standard climate zones using experimental design, Energy and Buildings 141 (2017) 1-15, ISSN 03787788, doi:10.1016/j.enbuild.2017.02.032.

[28] E. Rodrigues, N. Soares, M. S. Fernandes, A. R. Gaspar, Á. Gomes, J. J. Costa, An integrated energy performance-driven generative design methodology to foster modular lightweight steel framed dwellings in hot climates, Energy for Sustainable Development 44 (2018) 21-36, ISSN 09730826, doi:10.1016/j.esd.2018.02.006.

[29] Ren4EEnIEQ - Comprehensive BIM add-on tool for the improvement of energy efficiency and indoor environment quality in renovation of buildings, URL http://www.adai.pt/ren4eenieq/, 2016.

[30] EnergyPlus Version 8.8 Documentation: Input Output Reference Manual, Tech. Rep., U.S. Department of Energy, URL https://energyplus.net, 2017.

[31] Decreto-lei n. ${ }^{\text {o }}$ 80/2006. Regulamento das Características de Comportamento Térmico dos Edifícios (RCCTE), 2006.

[32] M. Kottek, J. Grieser, C. Beck, B. Rudolf, F. Rubel, World Map of the Köppen-Geiger climate classification updated, Meteorologische Zeitschrift 15 (3) (2006) 259-263, ISSN 09412948, doi:10.1127/0941-2948/2006/0130. [33] EnergyPlus, URL https://energyplus.net, 2017.

[34] E. Rodrigues, M. Fernandes, N. Soares, A. R. Gaspar, Á. Gomes, J. J. Costa, Dataset of generated and evaluated residential buildings of two storeys with random U-values for opaque and transparent exterior elements, doi: 10.6084/m9.figshare.5539810, URL https://goo.gl/iQnTXT, 2017.

[35] E. Maldonado (Ed.), Implementing the Energy Performance of Buildings Directive (EPBD): Featuring Country Reports 2016, ADENE, ISBN 978-972-8646-32-5, 2015. 